\title{
Synthesis of Silver Nanoparticles from Pleurotus florida, Characterization and Analysis of their Antimicrobial Activity
}

\author{
Tandeep Kaur ${ }^{1}$, Shammi Kapoor ${ }^{1^{*}}$ and Anu Kalia ${ }^{2}$ \\ ${ }^{1}$ Department of Microbiology, Punjab Agricultural University, Ludhiana 141004, \\ Punjab, India \\ ${ }^{2}$ Electron Microscopy and Nanoscience Laboratory, Department of Soil Science, Punjab \\ Agricultural University, Ludhiana 141004, Punjab, India \\ *Corresponding author
}

A B S T R A C T

\section{Keywords}

Antimicrobial activity,

Characterization,

Nanotechnology,

Pleurotus florida,

Silver nanoparticles

Article Info

Accepted:

28 June 2018

Available Online:

10 July 2018
In the present research, variable morphology of the silver nanoparticles (AgNPs) synthesized by using Pleurotus florida mycelia extract as a bioreductant at two different reaction conditions (shaking and static), has been reported. The formed AgNPs were characterized for the specific SPR (Surface Plasmon Resonance) peak position around 400 to $450 \mathrm{~nm}$ at different time intervals by UV-vis spectroscopy. Under shaking conditions silver nanoparticles took least time for synthesis. The particle/ aggregate size as deduced Transmission Electron Microscopy was in the range of 5-20 nm and 10-40 nm at shaking and static conditions respectively. The nano cyrstalline dimensions were further confirmed by X-ray diffraction (XRD) spectroscopy exhibiting the $2 \theta$ values corresponding to the face centered cubic crystal packaging of silver. The antibacterial potential of the synthesized silver nanoparticles showed effective inhibition of test pathogenic bacterial strains viz, Staphylococcus sp. and Bacillus sp.

\section{Introduction}

Edible mushrooms are used for nutritional and therapeutic purposes (Borchers et al.,2004, Chang 1996). They are perfect health foods as they are low in calories, fats, essential fatty acids and rich in vegetable proteins, vitamins and minerals (Murugkar and Subbulakshmi 2005). They are a rich source of natural antibiotics, where the cell wall glucans have immunomodulatory properties, and many secondary metabolites are known to kill bacteria, fungi and viruses (Gao, et al., 2005; Lindequist et al., 2005). Nanotechnology has recently become one of the most interesting research fields in technology and engineering for the purpose of manufacturing new materials at the nanoscale level (Albrecht et al., 2006)having potential applications in various areas such as chemicals, textile industries, materials industry, medical diagnostic, drug and gene delivery and electronics, diagnosis, artificial implants, tissues engineering (Kumar et al., 2011). It is well known that $\mathrm{Ag}^{+}$ions and $\mathrm{Ag}-$ based compounds have strong antimicrobial effects (Furno et al., 2004), and many investigators have shown nanoparticles to be effective antibacterial agents (Crabtree et al., 2003). Now-a-days, metal nanoparticles have 
been a subject of huge interest because of their unique physical and chemical properties. Metal/ metal oxide NPs have extremely high surface areas and unusual crystal morphologies that possess numerous edges or corner and other reactive surface sites. A wide variety of silver nanoparticle preparation techniques have been reported; notable examples include biological, chemical, electrochemical (Vorobyova et al., 1999), $\gamma$ radiation (Choi et al., 2005), photochemical (Li et al., 2005), laser ablation (Tsuji et al., 2003) etc. The physical and chemical methods involve high cost, require eco-toxic reagents and chemicals and therefore are noneconomical. As the use of toxic reagents for preparation of the NPs may corrode or cause adverse effect in the medical applications; scientists are looking forward for some low cost, non-toxic and eco-friendly route(s) of synthesis. Interest for biological mediated synthesis using plants, fungi, microbes and yeast (Philip et al., 2009; Tripathy et al., 2009) are gaining impetus. Since mushrooms have higher nutritious value besides possessing anti-cancer, -hypertension, diabetes and -high cholesterol properties (Ajith and Janardhanan 2007), these can be the model biological entities for generation of metal/ metal oxide NPs. The AgNPs have high specific area and high fraction of surface atoms, which will lead to excellent bactericidal effects (Mahendra et al., 2009). In this work we present the synthesis of silver nanoparticles from $P$. florida followed by their characterization using different spectroscopy and microscopy tools. The task of this work was to investigate the antimicrobial activity of the generated AgNPs against various human pathogenic bacteria.

\section{Materials and Methods}

\section{Culture procurement and maintenance}

The culture of Pleurotus florida was collected from Culture Collection Bank, Mushroom
Research Centre, PAU, Ludhiana. The culture was maintained on Potato Dextrose Agar slants at $25 \pm 2^{0} \mathrm{C}$ by sub-culturing them every month. The mycelia agar bits of approximately 5-6 $\mathrm{mm}$ diameter were sliced and picked from mother culture slants and transferred to potato dextrose broth and kept at $25 \pm 2{ }^{0} \mathrm{C}$ for growth of fungal mycelia.

\section{Chemical synthesis of silver nanoparticles}

The Ag NPs were chemically synthesized by two different methods i.e. Hot and Cold process. In hot process, $0.001 \mathrm{M}$ silver nitrate was boiled and tri-sodium citrate was added drop-wise to this solution along with vigorous stirring. The mixture was heated till development of pale brown color. Then the mixture was then cooled with stirring at room temperature. In cold process, $0.002 \mathrm{M}$ sodium borohydride was chilled on ice bath and silver nitrate was added drop-wise to it. The reaction mixture was stirred vigorously on a magnetic stirrer. The solution turned to light yellow and later to bright yellow by addition of all the silver nitrate.

\section{Biosynthesis of silver nanoparticles}

The mycelia extract was mixed with $\mathrm{AgNO}_{3}$ solution $(0.001 \mathrm{M})$. The mixture was incubated for 48 hours at different conditions (shaking and static) in the presence of sunlight for complete conversion of $\mathrm{AgNO}_{3}$ to AgNPs. Positive control (mycelia extract without $\mathrm{AgNO}_{3}$ ) and negative control $\left(0.001 \mathrm{M} \mathrm{AgNO}_{3}\right)$ were run simultaneously.

\section{UV-vis spectroscopy of aqueous suspension}

The samples were subjected to spectroscopy in the wavelength ranging from 300 to 600 $\mathrm{nm}$ using Double Beam Spectrophotometer (model Elico SL 159). The absorbance was plotted against the wavelength to observe the characteristic surface plasmon resonance peaks. UV-Vis spectra was generated at 
different time intervals and was used to compare the incubation conditions.

\section{Scanning electron microscopy (SEM)}

The morphology of synthesized NPs was deduced on a Scanning electron microscope (model Hitachi S-3400N) working at $15 \mathrm{kV}$ accelerating voltage. Samples were prepared by placing $10 \mu \mathrm{l}$ of the sample on the stub followed by gold coating in a gold ion sputter coater (model Hitachi E-1010). Elemental composition and the percentage of atom and weight of metals present on the sample surface were analyzed by SEM-EDS (model Thermo Noran).

\section{Transmission electron microscopy (TEM) using drop technique}

The nanoparticle size and structure was determined by Transmission electron microscope (model Hitachi H-7650) operated at $80 \mathrm{kV}$ in high contrast imaging mode. Samples were prepared by placing 10-20 $\mu \mathrm{l}$ of the sample on carbon/ formvar coated copper grid and were air dried before imaging in the microscope.

\section{X-Diffraction Spectroscopy (XRD)}

The purified nanoparticles were freeze dried at $-50^{\circ} \mathrm{C}$ under vacuum. The dried AgNPs were coated on XRD grid and diffraction pattern was analyzed using X-ray diffractometer (model XPERT-PRO) with anode material as $\mathrm{Cu}, \mathrm{K}-\alpha$ radiation at 1.54 . $^{\circ} \mathrm{A}$ working at $45 \mathrm{kV}$ and current $40 \mathrm{~mA}$. The samples were scanned at an angle between $2 \theta=20^{\circ}-70^{\circ}$.

\section{Determination of antimicrobial activity} against pathogenic bacteria

The antimicrobial susceptibility of chemically and biologically synthesized NPs was evaluated against five pathogenic bacteria namely Aeromonas hydrophila MTCC 1739, Bacillus cereus MTCC 430, Shigella flexneri MTCC 1457, Staphylococcus aureus MTCC 96 and Yersinia enterocolitica MTCC 859 using disc diffusion method. The zones of inhibition were measured after 24 hours of incubation at $35^{\circ}$ C. Four antibiotics (Amikacin, Ampicillin, Cefotaxime and Gentamycin) were also tested for their activity against the test microorganism.

\section{Results and Discussion}

\section{Biosynthesis of Silver Nanoparticles}

Synthesis of AgNPs was observed when mycelial extract was incubated with aqueous solution of silver nitrate, a gradual change of color was observed after half an hour (Fig. 1). The control treatments comprised of mushroom extract in deionized water (positive control) and $\mathrm{AgNO}_{3}$ salt in deionized water (negative control) remained colourless.

The silver nitrate treated mushroom extract turned brown in color. The color change could be due to the formation of silver nanoparticles of varying shape and size (Sudhakar et al., 2014)and can be attributed to excitation of surface plasmon resonance (SPR) peaks of the nobel metal nanoparticles (Narasimha et al.,2011).

\section{UV-vis spectroscopy}

The absorption spectra of AgNPs at different incubation conditions is presented in Fig. 2.shows the surface plasmon band at 430-440 $\mathrm{nm}$ indicating the production of AgNPs. Characteristic peaks in the range of 200-500 $\mathrm{nm}$ gives the evidence for the formation of NPs (Kaviya et al., 2011). AgNPs have generally been reported to show peaks in 400$500 \mathrm{~nm}$ wavelength range (Lee and El-Sayed 2006). The method of synthesis at shaking 
conditions took less time as compared to static conditions.

\section{Scanning electron microscopy (SEM)}

The representative SEM images of the mycosynthesized AgNPs (Fig. 3) clearly showed the presence of nanoparticles in both aggregated and dispersed form. The size diameter of the nanoparticles has been observed to lie between 10 to $30 \mathrm{~nm}$ and the shapes were observed as spherical. Similar observation in the size range 20-50 nm was reported by Vanmathi et al., (012). Similarly, Balashanmugam et al., (2013) reported that SEM analysis of nanoparticles sythesized from a mushroom revealed the spherical nature of silver nanoparticles and size distibuted in the range of $40 \mathrm{~nm}$.

\section{Transmission electron microscopy (TEM)}

The TEM image of the AgNPs indicated the formation of spherical nanoparticles with a few agglomeraions (Fig. 4). The average size of these nanoparticles at shaking and static conditions is $12.7 \mathrm{~nm}$ and $26.8 \mathrm{~nm}$ respectively.

The particle size histogram show that the particles range in the size from 5-20 nm and $10-40 \mathrm{~nm}$ at shaking and static conditions respectively.

\section{X-Ray diffraction (XRD)}

The crystalline nature of silver nanoparticles was confirmed by XRD spectroscopy (Fig. 5). Diffraction patterns at $2 \varnothing$ values 38.023 , $44.6113,46.093,68.483$ and 67.523 indicated the reflections of metallic silver (Kalpana and Lee 2013). Along with the five peaks mentioned above some other unassigned peaks were also observed at $27.74,32.11$, 33.77, 41.352, 54.394 and 57.58. The high intensity of these peaks indicated strong $\mathrm{X}$ ray scattering in crystalline phase (Shankar $e t$ al., 2003).

Table.1 Actimicrobial activity of AgNPs synthesized from Pleurotus florida (mycelia) compared to chemically synthesized nanoparticles a against pathogenic microorganisms as diameter of inhibition zones

\begin{tabular}{|c|c|c|c|c|c|}
\hline Synthesized AgNPs & $\begin{array}{l}\text { Aeromonas } \\
\text { hydrophila }\end{array}$ & $\begin{array}{l}\text { Bacillus } \\
\text { cereus }\end{array}$ & $\begin{array}{l}\text { Shigella } \\
\text { flexneri }\end{array}$ & $\begin{array}{l}\text { Staphylococcu } \\
\text { saureus }\end{array}$ & $\begin{array}{l}\text { Yersinia } \\
\text { enterocolitica }\end{array}$ \\
\hline $\begin{array}{c}\text { Pleurotus Mycelia AgNPs } \\
\text { (static conditions) }\end{array}$ & 22 & 36 & 18 & 34 & 24 \\
\hline $\begin{array}{c}\text { Pleurotus Mycelia AgNPs } \\
\text { (shaking conditions) }\end{array}$ & 32 & 35 & 20 & 39 & 25 \\
\hline Mean & 27 & 35.5 & 19 & 36.5 & 24.5 \\
\hline Chemically syth. AgNPs & 48 & 38 & 18 & 42 & 33 \\
\hline C.D @ 5\% & $\mathbf{8 . 1 1}$ & $\mathbf{6 . 9 2}$ & $\mathbf{4 . 4 7}$ & $\mathbf{3 . 9 9}$ & $\mathbf{7 . 0 6}$ \\
\hline Amikacin & 60 & 62 & 33 & 50 & 40 \\
\hline Ampicillin & 30 & 59 & 28 & 45 & 65 \\
\hline Cefotaxime & 40 & 40 & 20 & 50 & 55 \\
\hline Getamycin & 44 & 50 & 25 & 40 & 48 \\
\hline Mean & 45.33 & 48.66 & 24.6 & 44.33 & 38.5 \\
\hline C.D @ 5\% & $\mathbf{8 . 1 1}$ & $\mathbf{6 . 9 2}$ & $\mathbf{6 . 4 7}$ & $\mathbf{N S}$ & $\mathbf{7 . 0 6}$ \\
\hline & & & & & \\
\hline
\end{tabular}


Fig.1 Colour change as exhibited by incubation of silver nitrate solution before and after exposure to mycelia extract of $P$. florida

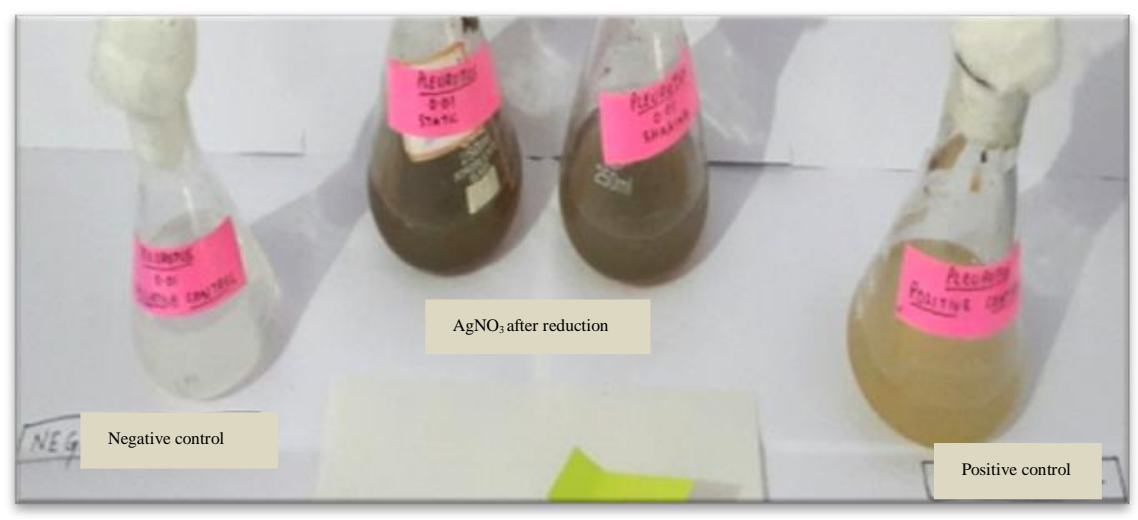

Fig.2 UV-visible spectrum at different incubation conditions (a) shaking (b) static
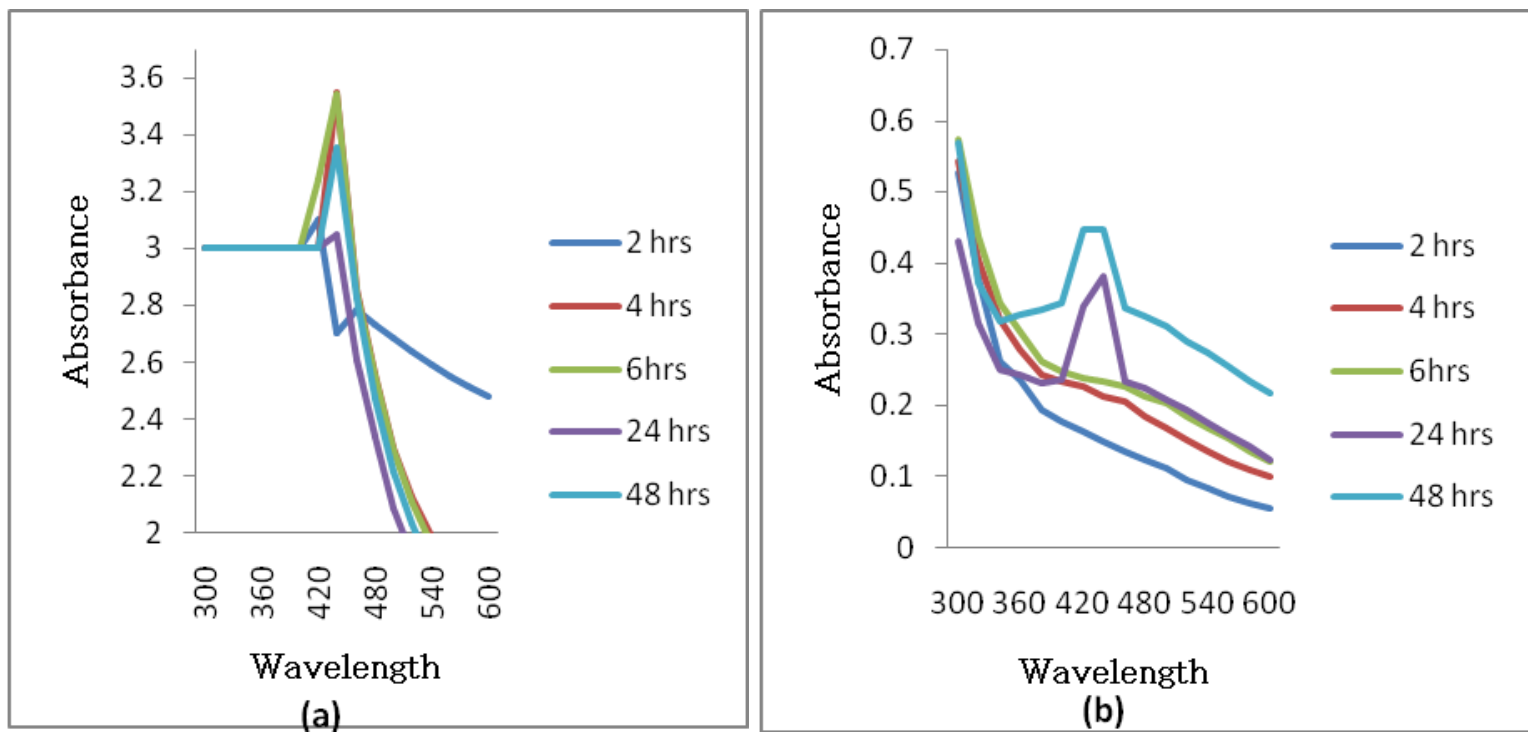

Fig.3 Scanning electron micrographs of Pleurotus florida synthesized silver nanoparticles at different incubation conditions (a) shaking (b) stati

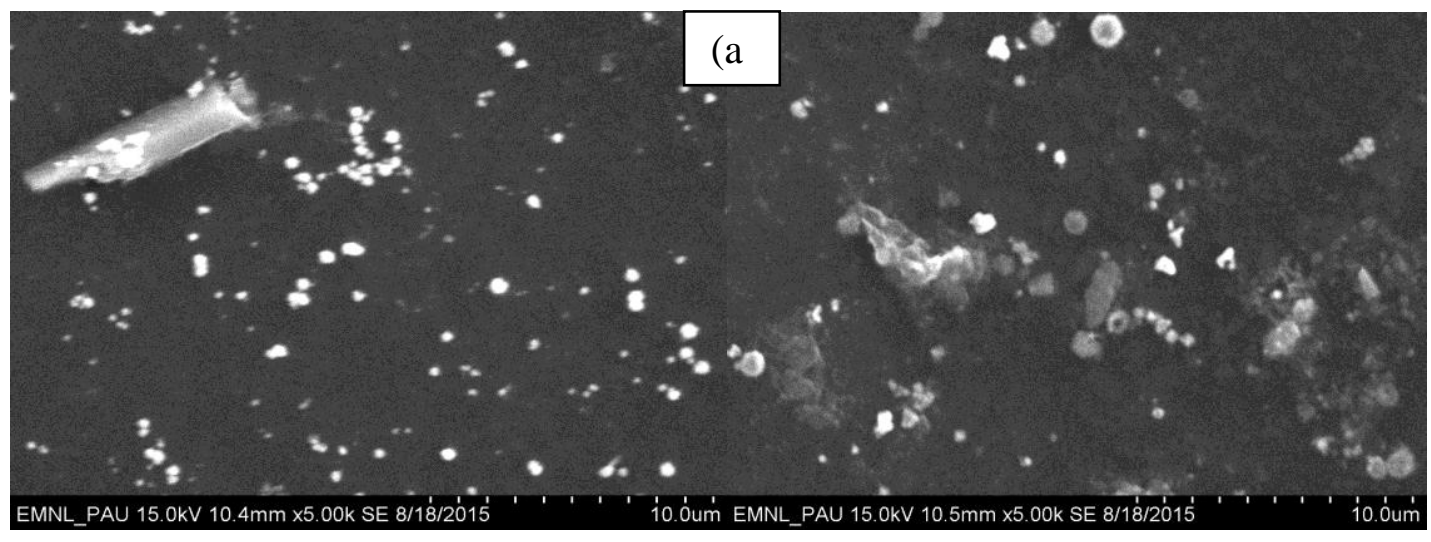




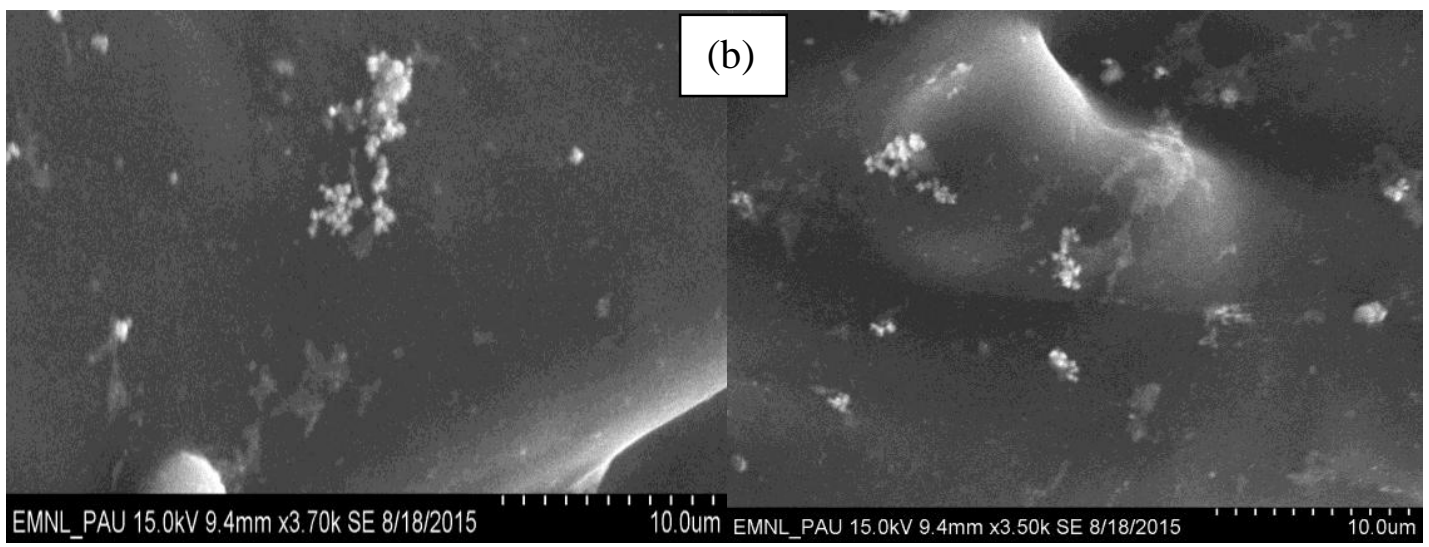

Fig.4 Transmission electron micrographs and particle size distribution of Pleurotus florida synthesized silver nanoparticles at different incubation conditions (a) static (b) shaking
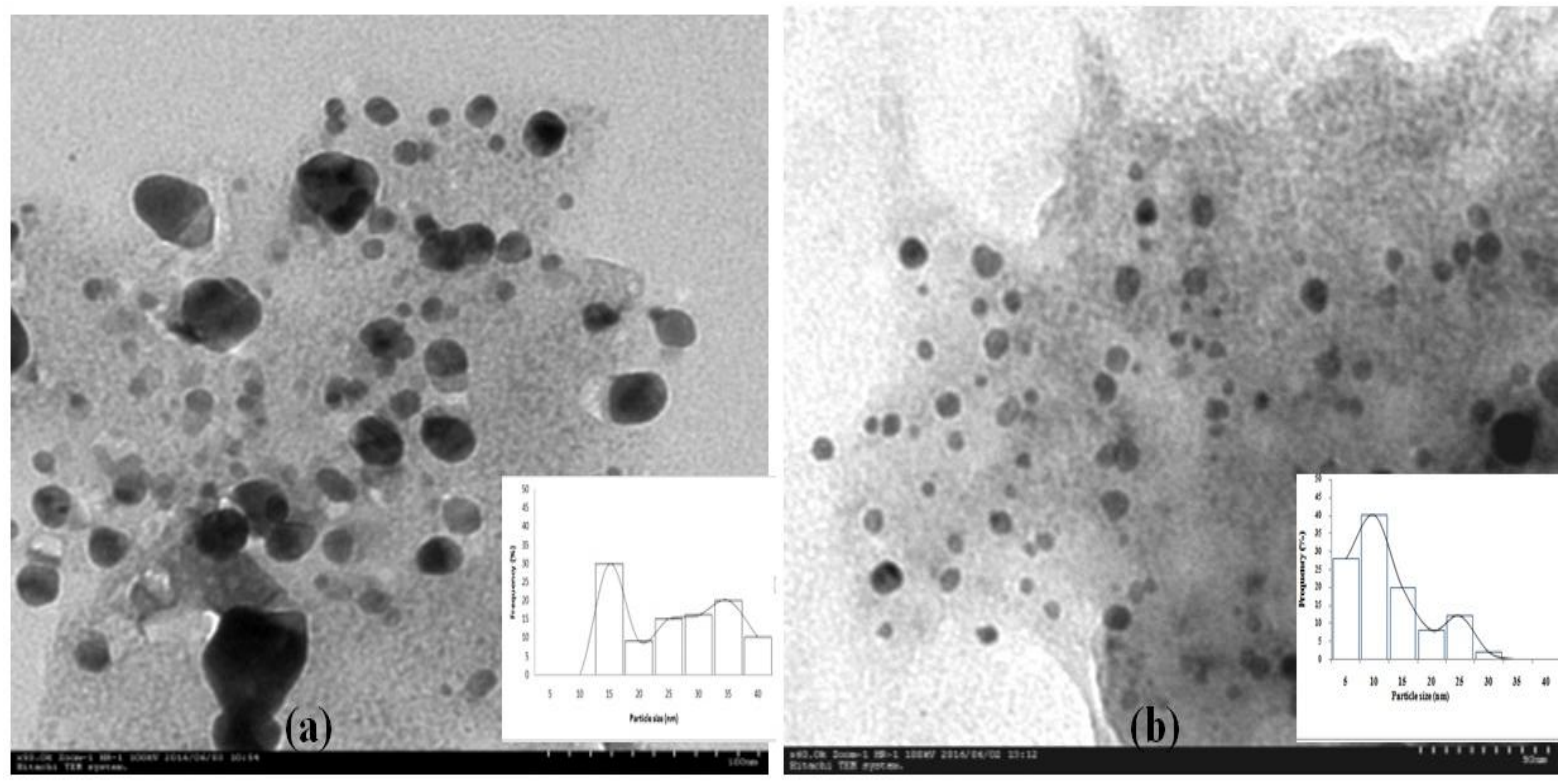

Fig.5 XRD spectra of Pleurotus florida synthesized Silver nanoparticles

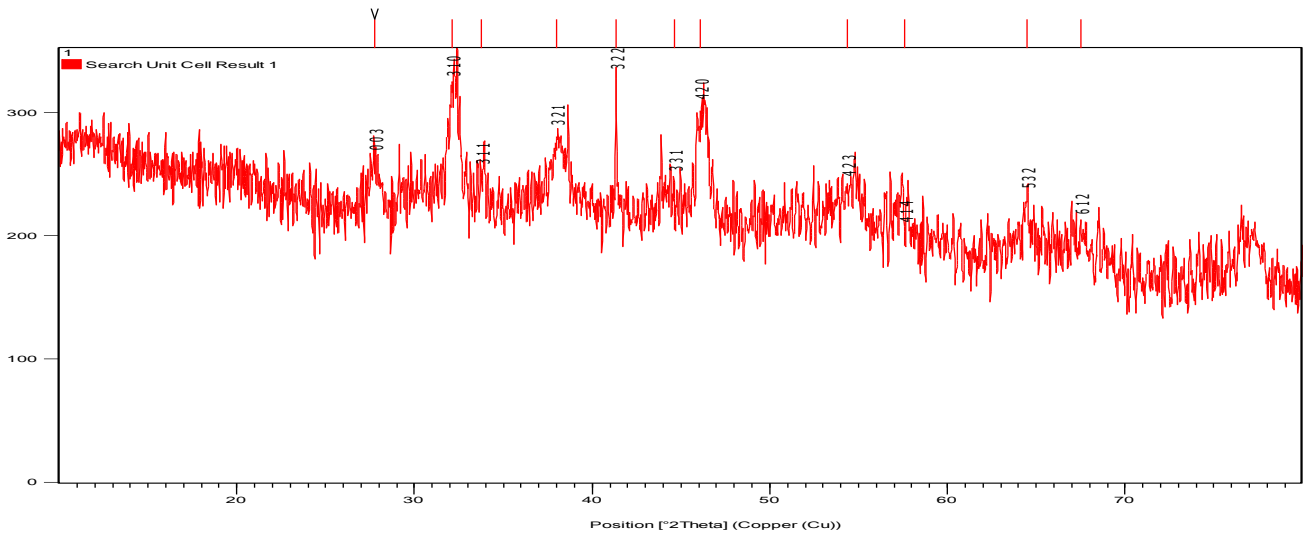


Fig.6 Antimicrobial activity of synthesized Ag NPs against (a) Staphylococcus aureus (b) Shigella flexneri (c) Bacillus cereus(d) Aeromonas hydrophila (e) Yersinia enterocolitica

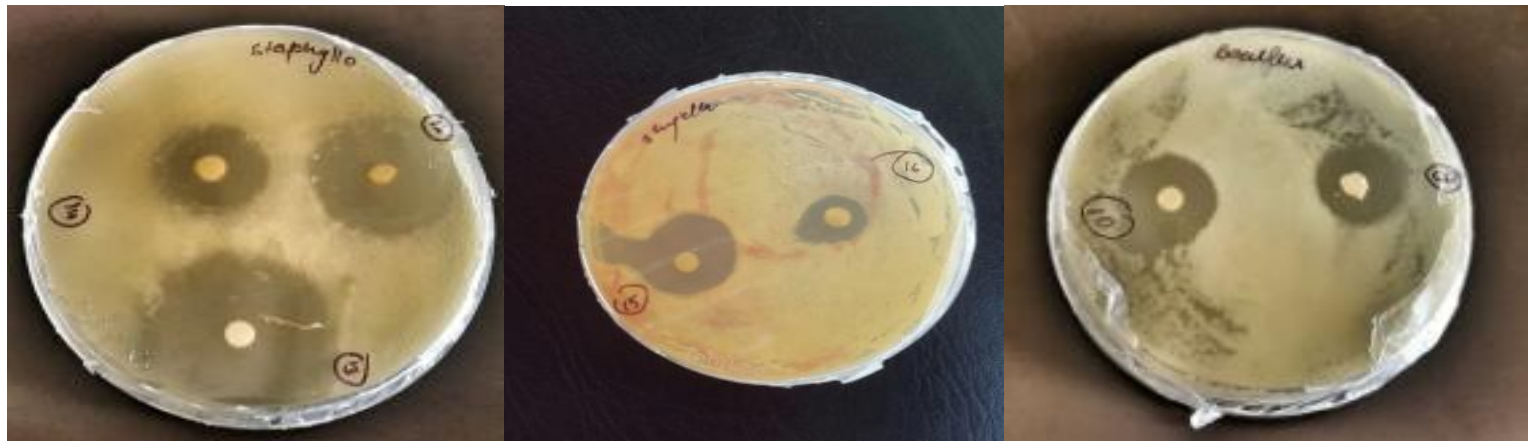

(a)

(b)

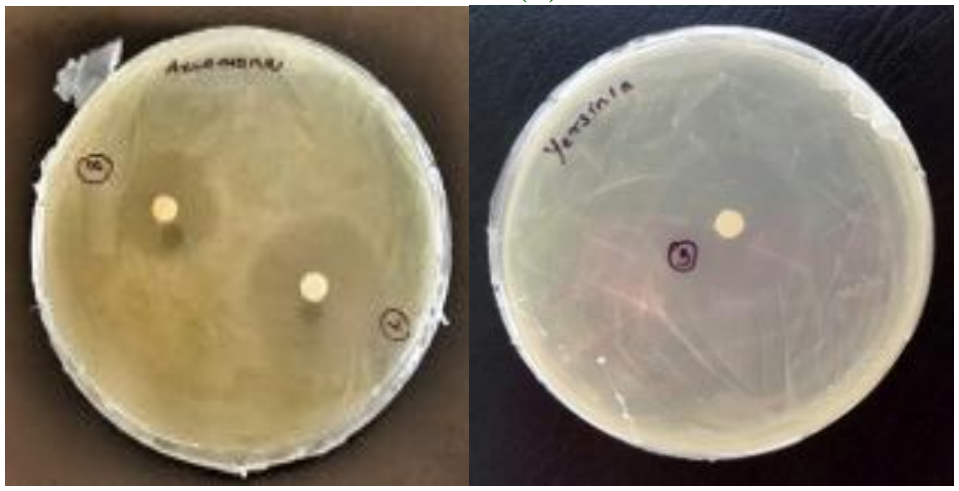

(d)

(e)

(c)

\section{Antimicrobial} nanoparticles

The antibacterial effects of biologically synthesized silver nanoparticles have been investigated against five pathogenic bacteria. Fig. 6 provides the insights into the activity of microbially synthesized silver nanoparticles against various pathogenic bacteria. The highest zone of inhibition was shown against Staphylococcus, second mean inhibition zone was found against Bacillus and lowest activity was found against Shigella (Table 1).

The highest zones of inhibition were against gram positive microorganisms Bacillus cereus and Staphylococcus aureus than gram negative microorganisms. Similar results were given by Guzman et al., (2009) that the Ag NPs showed good antibacterial action against gram positive organisms Bacillus cereus and
Nanoparticles are considered as novel biocidal and antimicrobial agents. They possess unique physical, chemical and biological properties. AgNPs have high specific area than their volume, which lead to their excellent antimicrobial activity as compared with bulk silver metal (Mahendra et $a l ., 2009)$. Chemical synthesis methods lead to presence of some toxic chemicals that get absorbed on the surface and may lead to adverse effect in the medical applications. (Singh and Singh 2010). Therefore, researchers are showing much interest on biological mediated synthesis using plants, fungi, microbes and yeast (Philip et al., 2009; Tripathy et al., 2009). Extracts from bioorganisms may act both as reducing and capping agents in Ag NPs synthesis.. There 
are various routes for the synthesis of NPs exhibiting homogeneity in their morphology and other properties. The microbial synthesis is cost effective, economically safe and environment friendly as compared to chemical and physical methods. AgNPs are the most promising nanomaterials having pronounced and documented antimicrobial activity. The present study is aimed to focus on the biological synthesis of AgNPs by using edible mushroom extract as bioreductant. The biosynthetic method developed in this study for producing silver nanoparticles has distinct advantage over chemical methods such as high bio-safety and being eco-friendly and non-toxic to the environment. There is a growing need to develop clean, nontoxic and environmentally friendly procedures for synthesis and assembly of nanoparticles, biosynthesis of silver nanoparticles using plants, bacteria (Kaliswaralal et al., 2008), fungi (Jaidev and Narasimha 2010) and yeast (Kowshik et al., 2003) are known to reduce silver ions into silver nanoparticles by both extra and intracellularly (Bhainsa and D'souza 2006).

Microbial synthesis of Ag NPs was performed using the cell free extract of Pleurotus florida along with the wet chemical synthesis of AgNPs and their antimicrobial potentials discerned at varying working concentrations. The extracts were treated with silver nitrate and placed under in different conditions for the appearance of color change. The synthesized nanoparticles were characterized by various microscopy and spectroscopy techniques. The UV-Vis spectroscopy of the synthesized sols exhibited characteristic absorption/ surface plasmon resonance peaks for the formation of AgNPs. Observation of this strong but broad surface plasmon peak has been well documented for various MeNPs, with sizes ranging all the way from 2 to 100 nm (Sastry et al., 1997; Sastry et al., 1998). The Plasmon peak was observed between 420-460 nm. SEM analysis confirmed the formation of AgNPs and revealed their spherical nature. TEM photographs revealed that the nano sols consist of well dispersed particles with size ranging from 5-40 $\mathrm{nm}$.

AgNPs have proved to be most effective because they have good antimicrobial activity against bacteria, viruses and other eukaryotic microorganisms (Gong et al., 2007). The synthesized nanoparticles were exhibited greater variability in their antimicrobial potentials. It is well known that $\mathrm{Ag}$ ions and Ag-based compounds are highly toxic to microorganisms, showing strong biocidal effects on as many as 12 species of bacteria including E. coli (Zhao and Stevens 1998). Recently, researchers have showed that hybrids of Ag nanoparticles with amphiphilic hyper-branched macromolecules exhibited effective antimicrobial surface coating agents (Aymonier et al., 2002). The microbially synthesized AgNPs exhibited maximum antimicrobial activity against gram positive bacteria Bacillus cereus and Staphylococcus aureus as compared to gram negative bacteria Shigella flexneri, Aeromonas hydrophila and Yersinia enterocolitica. On the contrary, chemically synthesized AgNPs showed highest zone of inhibition against gram negative bacteria. The microbially synthesized AgNPs showed significant antimicrobial activity against all the four test pathogens but showed less inhibition against Shigella flexneri. Kaviya et al., (2011) reported that the AgNPs exhibited good antibacterial activity against both gram negative and gram positive bacteria. But they showed higher antimicrobial activity against $E$. coli and $P$. aeroginosa (Gram negative) than $S$. aureus (Gram positive).The chemical controls showed less antimicrobial activity in comparison to synthesized NPs demonstrating that the metal ion toxicity has lesser antimicrobial potential than the 
nanoparticulate metal/ metal oxide particles. The zones of inhibition formed in antimicrobial screening test indicated that AgNPs synthesized in this process has the efficient antimicrobial activity against pathogenic bacteria. The biologically synthesized nanoparticles could be of immense use in medical field for their antimicrobial function.

\section{References}

Ahmad R, Fakhimi A, Hamid R, Minaian S, 2007. Synthesis and effect of silver nanoparticles on antimicrobial activity of different antibiotics against Staphylococcus aureus and Escherichia coli. Journal of nanomedicine research 3: $168-171$.

Ajith T A,Janardhanan K K, 2007. Indian medicinal mushrooms as a source of antioxidant and antitumor agents. Journal of Clinical Biochemistry and nutrition 40: 157.

Albrecht MA, Evans CW, Raston CL, 2006. Green chemistry and the health implications of nanoparticles. Green Chemistry 8: 417-32.

Aymonier C, Schlotterbeck U, Antonietti L, Zacharias P, Thomann R, Tiller JC, 2002. Hybrids of silver nanoparticles with amphiphilic hyperbranched macromolecules exhibiting antimicrobial properties. Journal of Chemical Communications 24: 3018-19.

Balashanmugam P, Santhosh S, Giyaullah H, Balakumaran M D, Kalaichelvan P T, 2013. Mycosynthesis, Characterization and Antibacterial Activity of AgNPsFrom Microporus Xanthopus: A Macro Mushroom. International Journal of Innovative Research Science Engineering and Technology 2: 626270 .

Bhainsa KC, D'Souza SF, 2006.Extracellular biosynthesis of silver nanoparticles using the fungus Aspergillus fumigatus. Colloids and Surfaces B: Biointerfaces 47: 160-164.

Borchers A T, Keen C L, Gershwin M E, 2004. Mushrooms, tumors, and immunity: an update. Journal of Experiment Biology and Medicine 229: 393

Chang R, 1996. Functional properties of edible mushrooms. Nutrition Reviews 54: S91-S93.

Choi SH, Zhang YP, Gopalan A, Lee KP, Kang HD, 2005. Preparation of Catalytically Efficient Precious Metallic Colloids by $\gamma$-irradiation and Characterization. Colloids and Surfaces A: Physiochemical and Engineering 256: $165-170$.

Crabtree JH, Burchette RJ, Siddiqi RA, Huen IT, Handott LL, Fishman A, 2003. The efficacy of silver-ion implanted catheters in reducing peritoneal dialysisrelated infections. Peritonal Dialysis International 23: 368-374.

Furno F, Morley KS, Wong B, Sharp BL, Arnold PL, Howdle SM, 2004. Silver nanoparticles and polymeric medical devices: a new approach to prevention of infection. Journal of Antimicrobial Chemotherapy 54:1019- 24.

Gao Y, Tang W, Gao H, Chan E, Lan J, Li X, Zhou S, 2005. Antimicrobial activity of the medicinal mushroom Genoderma. Food Reviews International 21: 211229.

Gong P, Li H, He X, Wang K, Hu J, Tan W, 2007. Preparation and antibacterial activity of $\mathrm{Fe} 3 \mathrm{O} 4$ @ Ag nanoparticles. Journal of Nanotechnology 18: 604611.

Guzman MG, Dille J, Godet S. 2009. Synthesis of silver nanoparticles by chemical reduction method and their antibacterial activity. Internaational Journal of Chemical and Biomolecular Engineering 2: 104-111. 
Iwalokun, BA, Usen UA, Otunba AA, Olukoya DK, 2007. Comparative phytochemical evaluation, antimicrobial and antioxidant properties of Pleurotus ostreatus. African Journal of Biotechnology 6: 1732-39.

Jaidev LR, Narasimha G, 2010. Fungal mediated biosynthesis of silver nanoparticles, characterization and antimicrobial activity. Colloids and Surfaces B: Biointerfaces 81: 430- 433.

Kalishwaralal K, Pandian R, Babu S, Venkataraman D, Bilal M, Gurunathan S, 2008. Biosynthesis of silver nanocrystals by Bacillus licheniformis. Colloids and Surfaces B: Biointerfaces 65:150-153.

Kalpana D, Lee YS, 2013. Synthesis and characterization of bactericidal silver nanoparticles using cultural filtrate of stimulated microgravity grown Klebsiella pneumonia. Enzyme and Microbial Technology 52: 151-156.

Kaviya S, Santhanalakshmi J, Viswanathan B, Muthumary J, Srinivasan K, 2011. Biosynthesis of silver nanoparticle using Citrus sinensis peel extract and its antibacterial activity. Spectrochimica Acta part A: Molecular Spectroscopy 79: 594-598.

Kowshik M, Ashtaputre S, Kharrazi S, Vogel W, Urban J, Kulkarni SK, Paknikar KM, 2003. Extracellular synthesis of silver nanoparticles by a silver-tolerant yeast strain MKY3. Journal of Nanotechnology 14: 95-100.

Kumar T, Rahuman A, Rajakumar G, Marimuthu S, Bagavan A, Jayaseelan S, Zahir A, Elango G, Kamaraj C, 2011. Synthesis of silver nanoparticles using Nelumbo nucifera leaf extract and its larvicidal activity against malaria and filariasis vectors. Parasitology Research 108: 693-702

Lee K S, El-Sayed M A, 2006. Gold and silver nanoparticles in sensing and imaging: sensitivity of plasma response to size shape and metal composition. Journal of Physical Chemistry B 110: 19220-25.

Li Z, Li Y, Qian XF, Yin J, Zhu ZK, 2005. A Simple Method for Selective Immobilization of Silver Nanoparticles. Applied Surface Science 250: 109 116.

Lindequist U, Niedermeyer THJ, Julich WD, 2005. The pharmacological potential of Mushrooms. Journal of Alternative and Complementary Medicine 2: 285-299.

Mahendra R, Alka Y, Aniket G, 2009. Silver nanoparticles as a new generation of antimicrobials. Biotechnology Advances 27: 76-83.

Murugkar A D, Subbulakshmi G, 2005. Nutritional value of edible wild mushrooms collected from the Khasi hills of Meghalaya. Food Chemistry 89: 599-603.

Narasimha G, Praveen, Mallikarjuna K, Raju D P, 2011. Mushrooms (Agaricus bisporus) mediated biosynthesis of sliver nanoparticles, characterization and their antimicrobial activity. International Journal of Nano Dimension 2: 29-36.

Philip D, 2009. Biosynthesis of Au, Ag and $\mathrm{Au}-\mathrm{Ag}$ nanoparticles using edible mushroom extract. Spectrochimica Acta part A: Molecular Spectroscopy 73: 374-81.

Sastry M, Mayya K, Bandyopadhyay K, 1997. pH-dependent changes in the optical properties of carboxylic acid derivatized silver colloidal particles. Colloids and Surfaces A: Physiochemical and Engineering Aspects 127: 221- 28.

Sastry M, Patil V, Sainkar SR, 1998. Electrostatically controlled diffusion of carboxylic acid derivatized silver colloidal particles in thermally evaporated fatty amine films. Journal of 
Phyical Chemistry 102: 1404 -10.

Shankar SS, Ahmad A, Pasricha R, Sastry M, 2003. Bioreduction of chloroaurate ions by geranium leaves and its endophytic fungus yields gold nanoparticles of different shapes. Journal of Materials Chemistry 13: 1822-26.

Singh R, Singh N H, 2010. Medical Application of nanoparticles in Biological Imaging, Cell Labelling, Antimicrobial Agents and Anticancer Nanodrugs. Journal of Biomedical Nanotechnology 7: 489-503.

Tripathy A, Chandrasekaran N, Raichur A M, Mukherjee A, 2009. Process variables in biomimetic synthesis of AgNPs by aqueous extract of Azadirachta indica (Neem) leaves. Journal of Biomedical Nanotechnology 5: 93-98.

Tsuji T, Watanabe N, Tsuji, 2003. Laser Induced Morphology Change of Silver
Colloids: Formation of Nano-size Wires. Applied Surface Sciences 211: $189-193$.

Vanmathi K, Sivakumar, 2012. Isolation and Characterization of silver nanoparticles from Fusarium oxysporum. International Journal of Current Microbiology and Applied Sciences 1: 56-62

Vorobyova SA, Lesnikovich AI, Sobal NS, 1999. Preparation of Silver Nanoparticles by Interphase Reduction Colloids and Surfaces A: Physiochemical and Engineering 152: $375-379$.

Zhao G, Stevens SE (1998) Multiple parameters for the comprehensive evaluation of the susceptibility of Escherichia coli to the silver ion. Biometals 11: 27 - 32.

\section{How to cite this article:}

Tandeep Kaur, Shammi Kapoor and Anu Kalia. 2018. Synthesis of Silver Nanoparticles from Pleurotus florida, Characterization and Analysis of Their Antimicrobial Activity. Int.J.Curr.Microbiol.App.Sci. 7(07): 4085-4095. doi: https://doi.org/10.20546/ijcmas.2018.707.475 